\title{
Sophie Masson
}

\section{Breaking the pattern: Established writers undertaking creative writing doctorates in Australia}

\begin{abstract}
The focus of this article is an examination of the experiences of established writers who have recently completed, or are currently undertaking, a creative writing doctorate, against a background of change within the publishing industry. Is it primarily financial/career or creative control concerns that are influencing established writers to undertake creative doctorates in recent times? And how do these writers fare within the degree program? To explore these issues through individual stories, interviews were conducted, by email and phone, with six established professional writers who had recently completed, or were still undertaking, a creative doctorate as well as with four established creative writing academics, most of whom are authors themselves. Questions of motivation and experience, as well as outcome, are canvassed in this piece of original research, which provides an interesting snapshot of the current situation for established writers in Australia undertaking creative writing doctorates. Keywords: creative writing doctorates, creative writing PhDs, publishing creative writing PhDs
\end{abstract}

\section{Introduction}

In 2001 Nigel Krauth, writing in TEXT, observed that there were only eight universities in Australia offering creative writing doctorates, as against 37 offering creative writing degrees at lower levels than the doctorate (Krauth 2001). Just eight years later, however, much had changed. In her paper, Describing the creative writing thesis: a census of creative writing doctorates, 1993-2008 published in TEXT in 2009, Nicola Boyd reported that 27 Australian universities offered a variant of the creative writing doctorate, with 199 creative writing PhDs, DCAs, and doctorates awarded between June 1993, when the first one (to Graeme Harper at UTS) was awarded, to June 2008, when her survey ended. The likelihood for publication of the work completed within a creative writing doctorate was high, with a 54 percent chance of trade or academic book publication. As Boyd points out, 'creative works from creative writing doctorates are very attractive to publishers as the development of the manuscript has already been supervised and assessed' (Boyd 2009).

According to Boyd's research, 75 percent of all authors awarded a creative writing doctorate were published in some way, either academically or creatively, before they received their award. The article's scope did not extend to examining at what stage of their writing careers the authors were when they undertook the doctorate - whether emerging, developing or established. But a much more recent set of figures provided by Dr Tom Longden of Macquarie University, and extracted from figures published in Macquarie University's Department of Economics' wide-ranging 2015 survey, Book Authors and their Changing Circumstances, indicates that of the 993 Australian authors included in the survey, 55 had a creative writing doctorate, with 22 of those describing themselves as established, and 21 as developing. While these numbers are small, and there was no way to identify when the degrees had been awarded, they are nonetheless interesting, indicating that established writers comprised 40 percent of those awarded creative doctorates (Longden et al 2015).

However, the focus of this article is not on the numbers of established writers either with, or undertaking, a creative writing doctorate, but rather on the motives and experiences of those who have recently undertaken such study, as well as outcomes for individual writers. It arose out of an initial perception that in a time of turmoil within the publishing industry and its consequent impact on authors' incomes, careers, and creative control, coupled with cuts in arts funding grants, established writers may be more interested in enrolling in creative writing doctorates.

Of course, the need to balance the freedom of writers' creative and intellectual expression and the commercial realities of the ever-evolving publishing marketplace has always existed, and there has never been a time when it's been easy to be a professional writer. But change has only accelerated within the worldwide publishing industry in the last five-ten years, as evidenced in the interviews of established authors and industry professionals published in The Adaptable Author: Coping with Change in the Digital Age (Masson 2014). 
The impact on authors worldwide of these transformations has been severe. The latest figures in the UK, from the Authors' Licensing and Collecting Society in 2014, show that in 200540 percent of UK authors earned their income purely from writing; by 2013, this had fallen to just 11.5 percent, while in the US, authors' incomes fell by 24 percent since 2009, and for established writers - in this case, those who had been continuously published for more than 15 years - the decrease in income since 2009 was even greater: 47 percent (Authors' Licensing and Collecting Society 2014). In Australia the impact of the changes on writers' incomes and careers has not been felt equally across all genres, but has been particularly marked in literary fiction, children's literature and creative non-fiction. Furthermore, 52 percent of all authors surveyed reported that insufficient income was preventing them from writing more (Longden \& Zwar 2015). These financial/career problems are coupled with the issue of a perceived loss of creative control. One Australian author recently encapsulated the issue in this way:

You put your heart and soul into writing ... and increasingly the commerciality is the dominating decision for publication. Factors such as ability to market the book, author profile and social media skills are now as important as the craft. (quoted in Longden \& Zwar 2015)

So the core questions for the research were these: in a challenging publishing climate, is it primarily financial/career or, rather, creative control issues that are influencing established writers to take on creative writing doctorates? And how do they fare, both in terms of experience during the doctorate, and future outcomes?

To explore these issues through individual stories, interviews were conducted from May to October 2015, by email and phone, with four prominent creative writing academics, most of whom are authors themselves, and with six established authors who had recently completed, or were still undertaking, a creative writing doctorate. The interview questions for the academics centred on the nature and scope of the creative writing programs at their universities, and their own general observations on the motivations and experiences of established writers within a creative doctorate program. This was aimed at establishing a background understanding of the issues as seen from within the university creative writing centres. Interview questions for the authors, by way of contrast, focussed on individual evaluation of the doctorate and hinged around three main themes: motivation; experience; and outcome [1].

While the sample size for both groups is small, the interviews provide an interesting snapshot of the current situation for established writers in Australia undertaking creative writing doctorates.

\section{Cultural and creative enrichment or a defacto writing grant: views from the academies}

Are established writers increasingly taking on study within a creative writing doctorate program, and if so, why? Professor John Dale, from the University of Technology, Sydney, where the Creative Doctorate program is now 25 years old, pointed out that established writers had enrolled in the doctorate right from the beginning of the UTS degree, and continued to do so. DCA graduates from UTS include wellestablished writers such as Kate Grenville (who wrote The Secret River as part of her DCA)Sue Woolfe, Cathy Cole, John Scott, Mandy Sayer, Gaby Naher, Andy Kissane, Kathryn Heyman and Suzanne Falkiner. He observed that:

No doubt many of these established writers would have published their creative works with or without the support of a university environment, but would they have written these books nearly as well? Would they have included the same amount of in depth research? (Dale, private correspondence, email interview, 28 September 2015)

As to the motives for established writers undertaking the degree, he attributed them to:

Partly to apply for a scholarship but also the unique opportunity to belong to a community of writers, to receive feedback and guidance from experienced writers. To tackle a difficult historical work for instance. Or to write a book that requires substantial research and time. (ibid)

Associate Professor Debra Adelaide, also of UTS, did not believe that recent turbulent times had brought more established-writer students into the program, in fact quite the contrary:

It's my impression that the numbers of established writers enrolling in a DCA peaked five or six years ago, and we aren't getting anything like the demand we used to, perhaps because it's so much harder now to get an APA scholarship. (Adelaide, private correspondence, phone interview, 30 September 2015)

Her evaluation of established authors' motivations in undertaking the doctorate encapsulated both financial and creative concerns: 
They want an academic qualification; they want to fund the writing of a book through the scholarship; and they want to have the consistent feedback from their supervisor as editor/mentor. Very occasionally I get approached by someone who wants to do something different, but it's not common. (ibid)

The potential challenges for established writers used to a particular way of working were also raised by her:

The doctorate is not the same as a commercial book - which can of course be a good thing for someone who wants to be innovative and exploratory. But it's bad for someone who's used to a particular genre and wants to write in the same way. The idea of publication, I think, is a terrible distraction. (ibid)

Professor Jeri Kroll at Flinders University also emphasised that caveat:

Established writers undertaking a PhD or DCA can find candidature a productive experience - if they want to embed themselves in a university environment and if they want to conceive of their new work as a research project. The experience tends to be difficult if writers really only want a de facto writing grant. (Kroll, private correspondence, email interview, 12 October 2015)

Professor Ivor Indyk at the University of Western Sydney, where the Writing and Research Centre has also attracted established authors since its beginning in 2006, said that he did not believe there had been any noticeable rise in these enrolments in very recent years. But the benefits of doing a degree were as worthwhile as they'd ever been:

Established writers who take on a creative doctorate have to be prepared to be critical and reflective about literature - and that is a good thing - it produces novelists and poets who can also write essays and criticism, and write across different genres. It enriches the literary culture in this way - that's the real benefit. (Indyk, private correspondence, email interview, 25 September 2015)

In summary, seen from within the academies, there is perceived to be little change in terms of numbers of established writers choosing to undertake creative writing doctorates. However, there is some concern expressed that the hybrid degree may simply be a substitute, for some writers, for literary grants which are increasingly difficult to obtain, or publishing contracts proving increasingly elusive. This perception underlies the observation that the increased difficulty in obtaining an APA scholarship makes it less likely, currently, that an established writer will follow through on an initial interest in undertaking a doctorate.

Of those writers who do decide to undertake a doctorate, financial/career concerns are seen as major influences on that decision. Issues of creative control, based on experiences of publishers' expectations, are also cited as common reasons for writers to undertake the degree, but some writers are perceived as also not wishing to accept the exigencies of the doctorate itself. As to whether experiences and outcomes will be positive or negative, these are seen as contingent on the writer-student's willingness to adapt their creative practice. The enrichment both of literary culture generally and a student's personal creative practice were seen as benefits that open-minded doctoral candidates could attain, while the academies themselves benefited from being associated with writers of high literary reputation.

\section{Creative control or career concern: motivations of writer-students}

Going from the general to the particular, and the individual experiences of established writers undertaking creative doctorates, and as might be expected, a nuanced and complex picture emerges. All six of the writers interviewed: Wendy James, Nick Earls, Donna Abela, Tony Davis, Kate Forsyth, Tony Davis and Stephen Dedman, had several books published or in Donna Abela's case, plays performed, before starting on the doctorate. All except for Wendy James, who transferred to part-time half-way through, undertook the degree full-time. The oldest doctorate was Stephen Dedman's, completed in 2008; the most recent is Nick Earls' ongoing degree, which is in its second year, while three - Tony Davis, Kate Forsyth, and Wendy James - completed in either late 2014 or early 2015, and Donna Abela was due to complete in late 2015.

Five of the authors had nominated the writing of a fiction project as the creative part of their doctorate with three, Wendy James, Kate Forsyth and Stephen Dedman, writing novels, and two, Nick Earls and Tony Davis, writing novellas, while Donna Abela's creative project was a play. All the creative projects are accompanied by exegeses. The creative work was the major part of nearly all the writers' doctoral theses, except for Tony Davis, who observed: 'During the PhD the theoretical aspects took over somewhat and what was to be a 50/50 theory-creative work project became $85 / 15^{\prime}$ ' (Davis, private correspondence, email interview, 28 October 2015). 
The writers' motives for undertaking the doctorate varied markedly, and in some cases echoed issues identified by the academics, while in others diverged or expanded from them. Stephen Dedman reported frankly that it was the prospect of a scholarship that enticed him in 2003, when he began his degree: 'I was approached by potential supervisors at two universities as I finished my MA, one saying "How would you like \$50,000 to write your next novel?"” (Dedman, private correspondence, email interview, 31 May 2015).

Kate Forsyth, however, wanted to follow a long-held intellectual interest:

I knew that no-one had yet examined the 'Rapunzel' fairy tale in depth, and there was room to make an original contribution to the field. I was also intrigued by the opportunity of really exploring my own personal engagement with fairy tales in a new and unexpected manner. (Forsyth, private correspondence, email interview, 29 May 2015)

For Wendy James, it represented not only an easing of financial strain, but also an opportunity to revisit previous academic work: 'I'd begun but not completed a PhD when I wrote my first novel, and had always felt terrible about that. It was also fabulous to have that little bit of financial security, and time to write' (James, private correspondence, email interview, 21 May 2015).

For Tony Davis, whose PhD focussed around an examination of the literary effects of second-person narration, accompanied by the creation of a novella, both practical and creative motives were involved:

As someone who earns my income through a combination of journalism and authoring books, embracing academia seemed a way of broadening my employability - at a time both my industries were in turmoil - as well as attempting a new and exciting challenge. By including an element that was creative, it enabled me to play to a strength while also learning about the theoretical aspects that I would need to master. A creative practice degree was also an opportunity to gain an income while writing experimental literature that was worthwhile but unlikely to realise any serious income. (ibid)

Donna Abela, whose PhD project was the creation of her play Jumping for Jordan, and its accompanying exegesis, wrote:

Starting with feminist theatre theory and practice, I explored various dramaturgical strategies for representing cultural difference and diversity on an Australian main stage (playwriting). Some projects you just know will need a deep and patient process, and peer support, so it was an opportunity to buy quality time in an environment which unequivocally supported arts practice and validated artists. (Abela, private correspondence, email interview, 15 October 2015)

Nick Earls' primary motive in undertaking a $\mathrm{PhD}$ was the freedom to explore his chosen form, both in writing and experimenting with publication: 'I really enjoy the novella form and wanted to write more. Also, I see the novella as having real opportunities it didn't have before, but using a very different approach to the industry standard.' The possibility of experimenting with different publishing platforms ebooks, audiobooks and print - also appealed to him:

I'm releasing the novellas in quick succession as a series on all three platforms, and tapping into my social media network as well as mainstream media to draw attention to the project. That wasn't going to be something I could persuade a big publisher to do, and a $\mathrm{PhD}$ seemed like a great forum to explore it and plan it in detail, and with some awareness of what the evidence says. It's allowed me to make the exploration of this core business, rather than a side interest. (Earls, private correspondence, email interview, 14 May 2015)

In the individual cases surveyed, the general trends noted by the academics were particularised in ways which both bore out much of what the academics had said, but also expanded on it. Only one of the writers interviewed, Tony Davis, explicitly cited being influenced by current publishing industry transformations as motivating him to decide to undertake a doctorate. None of the others mentioned that as a primary concern. However, financial and career concerns of one kind or the other were cited directly by four of the six writers, but only one, Stephen Dedman, explicitly stated that was his primary motivation.

When it came to the issue of creative control, however, this was cited in one way or the other by all the writers, which suggests that it is likely to be a strong motivation in the decision of an established writer to undertake a creative writing doctorate. Two other related motivations also emerged from the interviews, one of which was the desire to experiment, to try something new. The other, which reflects the reality of working life for many established writers in a publishing industry geared to fast and constant publication, is the possibility of taking time over their writing, to slowly build a creative work, and think about its intellectual and literary implications. These last two motivations can in fact also be seen as aspects of the 
bigger issue of creative control, which is broader than just resistance to publishing industry restrictions but also encompasses the need for intellectual challenge, and to explore depth and breadth within individual creative practice. In this way, the need for creative control, in all its aspects, can be seen as providing the most fertile base for the creation of work which would enrich individual creative practice, academic knowledge, and the wider Australian literary culture.

\section{Inhibiting or stimulating: individual experience of doctorates}

Just as motives varied, so did experiences during the degree. Confirming what Debra Adelaide observed about the challenges facing writers used to working in a certain way and reluctant to change that, Stephen Dedman reported that the experience was not a happy one, inhibiting his creative practice:

I found the prospect of writing a novel that would meet with the university's approval somewhat inhibiting, and second-guessed myself a lot, with the result that I'm less than happy with the novel. It took me more than two years to write, bore only occasional resemblance to the outline in my application for a candidacy, and I haven't even bothered shopping it around. (ibid)

However, he had also written two other novels during that time, both of which were published:

I found the research I'd done for the PhD novel useful for creating the mindset of some characters in both, but they have confirmed my suspicion that I'm much happier writing a first draft as quickly as possible from an outline that focuses on plot and characters rather than themes. (ibid)

For Wendy James, working within a PhD didn't really change the way she thought about the novel, or the way she wrote, but there were aspects that enriched her writing, while others were more challenging:

It certainly meant I could focus on the novel exclusively, and write it reasonably quickly. I think I had a first draft in about eighteen months. However, I found the exegesis just as difficult as I'd expected, and found it impossible to write until the novel was completed. Even then I found it difficult. I'm not a natural non-fiction writer ... sometimes it's a bit like pulling teeth. (ibid)

Donna Abela reported on a good experience over the five years of her PhD: 'I feel that I am better equipped to facilitate creative writing or play development processes, and to teach beyond traditional playwriting pedagogy. I think I have become a more courageous artist' (ibid).

Tony Davis remarked on a difficult allocation of time:

With regular journalistic commitments and various books in train at the same time, I needed to work long hours to keep the $\mathrm{PhD}$ moving forward, and to complete all the readings and other requirements of what was in effect full-time study. There were long times when I didn't complete any creative writing because of the mental demands of the PhD. When I did return to fiction I went through periods of overthinking structure, perspective, etcetera, and I lost some spontaneity and verve from my writing. Hopefully, I've now found the right balance. (ibid)

Kate Forsyth found the experience completely positive:

I enjoyed the whole experience from beginning to end. It was a little difficult at times to manage my writing deadlines as well as my academic deadlines, but I just knuckled down and did what had to be done. I don't think it changed my writing approach: I wrote the novel first and my exegesis afterwards. (ibid)

Nick Earls, in the second year of his $\mathrm{PhD}$, expressed great satisfaction with both the creative and intellectual aspects of the experience so far:

While a lot of my critical focus is on the industry side of it, I have also done significant reading around novella craft. I still want to turn out the best writing I can, I still want to keep getting better, and no one's set me any objectives for the creative part beyond that. I'm enjoying the thinking around it though, and looking into aspects of it and putting the plan together. Signing up for a PhD let me give myself permission to devote serious time to that. The experience certainly feels positive at the moment. I'm doing some writing I really want to do, I'm trying a few different publishing tactics and I have supervisors I can bounce ideas off any time I need to. (ibid)

Contrasts abound in this part of the interviews. The experience for some people leads to greater intellectual depth, for others, to fears about 'overthinking'. The issue of creative control is again important 
here: there is a sense from some that this is an opportunity to escape from one system (of publishing) from others a frustration of being hemmed in by another system (of academia). Some writers enjoy the opportunity of changing their way of working on their fiction; others are resistant to creative change.

It is also clear from the interviews that a writer-student's experience of their doctoral work stems largely on their original motivation, with a primarily financial motivation being the least likely to produce a positive experience and a willingness to adapt and challenge themselves within their creative practice being the one most likely to produce a positive experience. However, it is notable that though Stephen Dedman was the only one to express dissatisfaction with the original creative product of his doctorate due to academic restrictions, he was not the only one to express some unease about the undesirable way in which the academic product might impinge on the creative product. Nobody mentioned the reverse problem. In fact, two of the writers reported that the academic work had little influence on the creative product, as the latter was finished well before the former. It could be said that in those cases the creative product influenced the academic product, but not the other way around. This could be seen as problematic within the academies, given the emphasis in the doctorate programs to balancing the creative and academic products, and exploring the connections and disconnections between them. However, other writers in the survey evoked the interesting synergy between the two aspects of the degree, and the way this enriched their individual creative practice.

\section{Adapt by breaking the pattern: outcomes}

For the four writer-students who had completed their degrees, their evaluation of the outcomes revealed some interesting results, which bore out the view expressed in the academic interviews that adaptation was the key to a successful outcome. This was even the case when an actual doctoral experience had negative elements. As quoted above, during the time he was working on the $\mathrm{PhD}$, Stephen Dedman also wrote two other novels which have since been published, and his exegesis will also be shortly published, an outcome which he described as satisfactory. However, the novel he wrote during the $\mathrm{PhD}$ has not been published, and though he said he was more likely now to be asked to contribute to academic streams at science fiction conventions, having a $\mathrm{PhD}$ had: 'sometimes helped and sometimes hindered me in finding work as a sessional tutor - helped because the university didn't want me to starve while I was working on the $\mathrm{PhD}$, then hindered once I'd graduated because PhDs are paid more' (ibid).

The domestic suspense novel Wendy James wrote during her $\mathrm{PhD}$, The Mistake, was published to great acclaim in 2014 and she has also found other positive results coming out of successfully completing her degree: 'I think it does give me some sort of professional credibility. A friend and I have set up a creative writing school in Newcastle, and I think the fact that we both have doctorates, along with years of practical experience, adds something' (ibid).

Kate Forsyth's DCA novel, Bitter Greens, a novel blending history and fairy tale, which had been contracted on outline to a publisher even before she began her degree, has been a great success, both in Australia and internationally, garnering the American Library Association (ALA) Award for Best Historical Novel in 2014, and being shortlisted in several other awards. It is not just the very successful publication of her project though which has been a satisfying outcome to her undertaking the degree. As a recognised expert in fairy tales through doing her doctorate, she is regularly asked to contribute to programs on the subject on radio and TV, and invited to present papers: 'I think it has enriched my life and my working practices, and has enhanced my reputation as an expert in the field of fairy tale studies' (ibid).

Tony Davis has equally had significantly successful outcomes. Ohio State University Press has expressed interest in an adapted version of the exegesis on second person, and the creative portion, a novella called The Flight, was published in Griffith Review 50: Tall Tales Short (October 2015). He explained:

It was one of five selected in a blind review process from 270 entries, which I mention because it reinforces the fact that worthy fiction can be created in an academic context, even when that fiction is designed foremost to prove a set of findings from the research. Unlike in the MPhil which preceded it, where I went in with a novel I wanted to write and shaped the project around it, this creative piece followed the research and came wholly from it. The $\mathrm{PhD}$ has forced me to read more widely than I might have otherwise done and gain a greater appreciation of the technical aspects of writing. Has it made me a better writer? Hard to say, but it has certainly made me a better informed writer. (ibid)

At the time of the interview in late 2015, Donna Abela was in the final stages of writing up her exegesis, but she had already seen substantial results. Jumping for Jordan has already beenhonoured in multiple awards, including winning the 2015 AWGIE Award (Stage) and being shortlisted for the 2015 NSW Premier's Literary Awards (Multicultural NSW Award). She reported: 'I have been able to create an award-winning play which otherwise would never have seen the light of day. I feel much more assured of my practice, and have enriched my dramaturgical and critical skills' (ibid).

Finally, though he is still in the middle of his $\mathrm{PhD}$, Nick Earls is already seeing significantly good results: 
The novellas weren't under a contract at the start. I wanted to be free to look into all kinds of different opportunities, and a big part of it was discovering what those might be. At the moment, it's tracking ahead of expectations, and it's been a few years since I've been able to say something like that. (ibid)

In fact, by the time this article was finished, Earls' novellas were already contracted to an Australian print and ebook publisher, an audio book publisher, and an international ebook publisher, with the books to be released throughout 2016 [2].

Given that part of his exegesis focuses around the question of whether recent changes in technology make novellas a viable publishing proposition for mid-career, mid-list authors, these are substantial outcomes. Earls is not only looking to the future, but assessing what undertaking the $\mathrm{PhD}$ already means for him as a writer:

After twenty books, it's given me permission to do something different, think in a different way and work outside the system. It has given me a chance to think deeply about the novella form and commit to it, and to think rigorously about how it's been handled by the industry and how it might be handled. I'm loving the writing part of it, and I don't think my career is best served by simply turning out a novel every year. I might think each one is different, but people have become too used to the pattern. This breaks that pattern, and I think that's good. (ibid)

\section{Conclusion}

While it seems that the original premise in starting out on the research for this article - the perception that turmoil in the publishing industry may be increasingly pushing established writers into taking on a creative doctorate - is not borne out from either academic observation or individual student stories, it is clear that financial and career concerns do play a part in the decision to undertake a doctorate. But the issue of creative control appears to be a stronger motivation, including the opportunity of experimenting, of 'breaking the pattern', and having the time and mental space to do so.

For most of these established writers, 'breaking the pattern' in one way or the other through the period of doctoral study, stretching boundaries and exploring literary and professional options and ideas over time, is at the heart of the most successful and satisfactory experiences. Even if that does not include a complete change from previous creative practice, it involves a break from a pattern of literary life which had become unsustainable or unsatisfactory in one way or the other, refreshing a writer's outlook and options through contact with the academies.

On the question of outcomes, however, it is interesting to note that the very fact of having undertaken such a major study appears to make for satisfactory results. Working through the doctorate has given each of these six writers' outcomes of lasting value, even, perhaps surprisingly, when their student experiences have not been satisfactory. The time factor is also important: in allowing for the slow development of a creative work (when the current publishing climate frequently demands much faster development) the doctorate paradoxically seems to enable writers to achieve swifter results once the work is completed.

Such successful outcomes cannot fail to impact on writers' confidence, their continuing creative practice and their potential to enrich not only literary culture, but to help advance academic understanding of creativity. This also serves to highlight the continuing value of the creative writing doctorate to the academies: both in acquiring the individual insights and experience of professional creative writers and in turn allowing the academies to contribute directly to the development of the wider Australian literary world.

\section{Notes}

[1] Permission to quote from these email and phone interviews for the purpose of this article was sought from and granted by all interviewees. Interviews were conducted principally by email, between 14 May and 15 October 2015 with one exception, Debra Adelaide's interview, conducted by phone on 30 September 2015. return to text

[2] At the time of editing this article, three of the novellas had already been released, with substantial reviews and articles about them in major newspapers. return to text

\section{Works Cited}

Authors' Licensing and Collecting Society 2014 'New Research into authors' earnings released', ALCS (8 July): http:/www.alcs.co.uk/About-us/News/News/What-are-words-worth-now-not-much.aspx (accessed 19 September 2015) return to text 
Boyd, N 2009 'Describing the creative writing thesis: a census of creative writing doctorates, 1993-2008, TEXT 13, 1 (April): http://www.textjournal.com.au/april09/boyd.htm (accessed 10 July 2015) return to text

Krauth, N 2001 'The Creative Writing Doctorate in Australia: An Initial Survey', TEXT 5, 1 (April):

http://www.textjournal.com.au/april01/krauth.htm (accessed 10 July 2015) return to text

Longden, T, D Throsby \& J Zwar, J 2015 Book Authors and their Changing Circumstances, Macquarie University Department of Business and Economics (September):

http://www.businessandeconomics.mq.edu.au/our_departments/Economics/econ_research/reach_network/book_project/authors (accessed 19 September 2015) return to text

Longden, T \& J Zwar 2015 Authors' incomes, Australian Author Online: http://australian-author.org/online/authors-income (accessed 19 September 2015) return to text

Masson, S 2014 The Adaptable Author: Coping with Change in the Digital Age, Keesing Press, Sydney return to text

The Authors' Guild 2015 'The Wages of Writing', The Authors Guild: https:/www.authorsguild.org/industry-advocacy/thewages-of-writing/ (accessed 19 September 2015)

Sophie Masson is the award-winning writer of over sixty books for children, young adults and adults. Her most recent novel is Hunter's Moon (Random House Australia 2015). The holder of a BA and MLitt from the University of New England, she is currently undertaking a PhD in Creative Practice at the same university. She is on the Boards of the Australian Society of Authors, the New England Writers' Centre, and the Small Press Network.

\section{TEXT}

Vol 20 No 2 October 2016

http://www.textjournal.com.au

General Editor: Nigel Krauth. Editors: Kevin Brophy \& Enza Gandolfo text@textjournal.com.au 